\title{
On the Horizon
}

\section{Emotions run high as the European Commission's ambitious framework for research and development forms the focus of a special budget summit in Brussels.}

The jewel in the crown of the European Commission's seven-year budget set out in summer 2011 was, for many, Horizon 2020 - a pledge for $€ 80$ billion towards ensuring Europe's global competitiveness in research and innovation. Aimed at promoting excellence in science, the programme identifies the development of talent and research infrastructure as key areas for targeted funding, whilst stressing the need to establish Europe as an attractive destination for the world's best researchers.

As part of their promise to agree on elements of the budget framework by the end of 2012, the Council of the European Union scheduled an extraordinary summit of European heads of state for 22-23 November 2012. But in the wake of economic unrest, certain member states had threatened to make cuts in the Commission's proposal, prompting widespread concern over the fate of the framework.

Lobbying for Horizon 2020 gathered momentum late in October, when the European Parliament passed a resolution emphasizing "the need to enhance, stimulate and secure the financing of research and innovation" (available via http://go.nature.com/CMESuv) and issuing mild warnings to member states unwilling to co-operate. A letter in support of the proposal, signed by 54 Nobel laureates and five Fields Medallists, fanned the flames as did an online petition circulated by young researchers.

As Nature Physics goes to press, the outcome of this summit remains unclear. But a vote against such necessary measures would seem imprudent, particularly at so crucial a time for initiatives fostering economic growth.

\section{A century of Turing}

\section{As the 2012 celebration of Turing's life and work draws to a close, we highlight different events that showcase Turing's continuing influence on science, technology and art.}

Alan Turing is famously associated with the dawn of modern computing - so it's little wonder that his fascination with nature is often overlooked. But his seminal 1951 paper on morphogenesis, detailing reaction-diffusion theory, laid a cornerstone for research in theoretical biology. And in the same year, Turing mused that the spiral shapes on the heads of sunflowers seemed to follow the Fibonacci sequence, prompting his proposal that by studying sunflowers we might better understand how plants grow. Like much of his work, this pursuit was cut short by his untimely death in 1954. The hypothesis has now been put to the test some 60 years later, in one of many projects designed to celebrate the centenary of his birth.

We now know that the appearance of the Fibonacci series in seed-heads originates in the dynamics of plant growth. The structures that spiral out from the apex of a sunflower bud form an angle of around $137.5^{\circ}$ with one another. This is the so-called golden angle - the smaller of two angles formed in a circle divided by the golden section - which, incidentally, is also found in Romanesco broccoli, pine cones and artichokes, to name but a few. And now for the punchline: the approximate quotient of consecutive numbers in the Fibonacci series is given by the golden ratio.

A project launched in March 2012 has sought confirmation of this phenomenon.

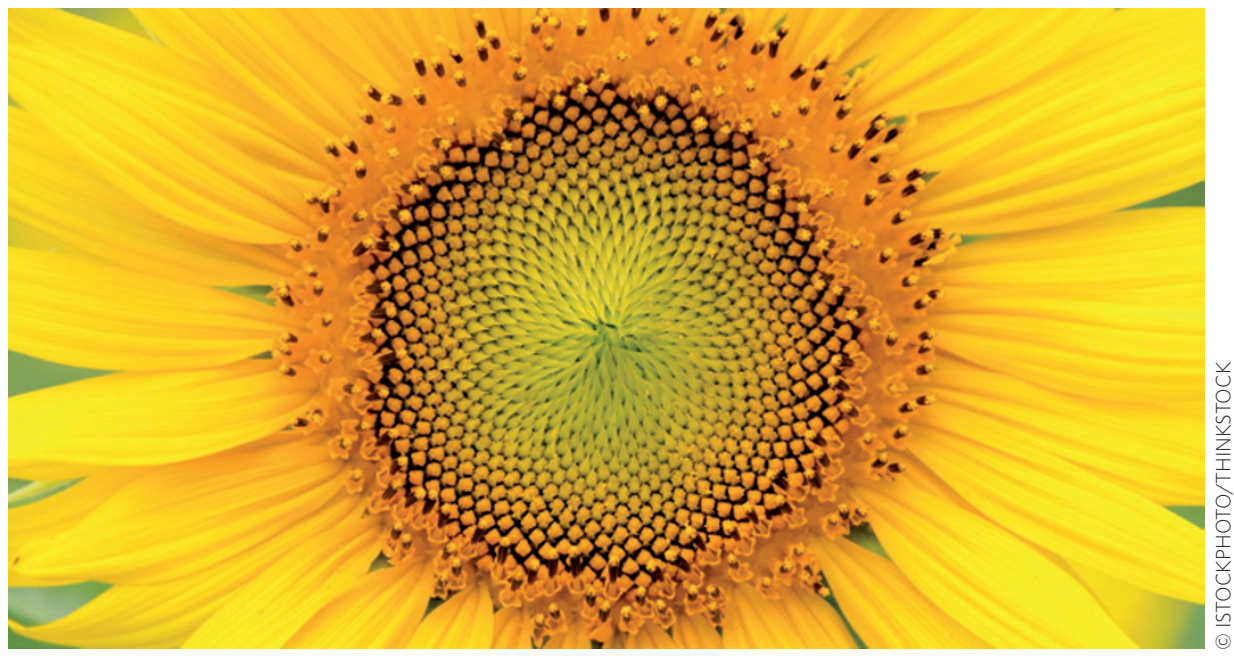

Chiefly planned as a tribute to Turing, the attempt constitutes the largest study of the mathematical patterns of sunflowers. People around the globe, including many schoolchildren, were enlisted to grow sunflowers and collect data on the patterns they observed, including the number of spirals running clockwise and anticlockwise in the seed head.

The result of the project was announced by its creator, Professor Jonathan Swinton, at the Manchester Science Festival in October. The combined statistics of 557 flowers indicated that eight out of every ten sunflowers exhibit patterns conforming to the Fibonacci series.

Our Books \& Arts section on pages $853-855$ of this month's issue is devoted to some of the other tributes to Turing. We review B. Jack Copeland's new biography Turing: Pioneer of the Information Age, which attempts to demystify the legend of Alan Turing. The short film The Creator by $\mathrm{AL}$ and AL takes that legend to another level, casting Turing as a tragic god. And finally, the Science Museum in London provides a small collection of tangible insights into his life and achievements. 